Article

\title{
Stand Diameter Distribution Modeling and Prediction Based on Maximum Entropy Principle
}

\author{
Yuling Chen, Baoguo $\mathrm{Wu}$ * and Zhiqiang Min \\ School of Information Science and Technology, Beijing Forestry University, Beijing 100083, China; \\ chenyuling92@163.com (Y.C.); minzq1026@163.com (Z.M.) \\ * Correspondence: wubg@bjfu.edu.cn; Tel.: 010-62338246-428
}

Received: 29 August 2019; Accepted: 26 September 2019; Published: 2 October 2019

\begin{abstract}
Research Highlights: Improving the prediction accuracy represents a popular forest simulation modeling issue, and exploring the optimal maximum entropy (MaxEnt) distribution is a new effective method for improving the diameter distribution model simulation precision to overcome the disadvantages of Weibull. Background and Objectives: The MaxEnt distribution is the closest to the actual distribution under the constraints, which are the main probability density distributions. However, relatively few studies have addressed the optimization of stand diameter distribution based on MaxEnt distribution. The objective of this study was to introduce application of the MaxEnt distribution on modeling and prediction of stand diameter distribution. Materials and Methods: The long-term repeated measurement data sets consisted of 260 diameter frequency distributions from China fir (Cunninghamia lanceolate (Lamb.) Hook) plantations in the southern China Guizhou. The Weibull distribution and the MaxEnt distribution were applied to the fitting of stand diameter distribution, and the modeling and prediction characteristics of Weibull distribution and MaxEnt distribution to stand diameter distribution were compared. Results: Three main conclusions were obtained: (1) MaxEnt distribution presented a more accurate simulation than three-parametric Weibull function; (2) the Chi-square test showed diameter distributions of unknown stands can be well estimated by applying MaxEnt distribution based on the plot similarity index method (PSIM) and Weibull distribution based on the parameter prediction method (PPM); (3) the MaxEnt model can deal with the complex nonlinear relationship and show strong prediction ability when predicting the stand distribution structure. Conclusions: With the increase of sample size, the PSIM has great application prospects in the dynamic prediction system of stand diameter distribution.
\end{abstract}

Keywords: stand diameter distribution; Weibull distribution; maximum entropy principle; parameter prediction method; parameter recovery method; plot similarity index method

\section{Introduction}

The study of stand diameter distribution model provides a scientific basis for determining wood types structure, the evaluation of forest resources and scheduling for future silviculture treatment [1-3]. Commonly, a diameter distribution model is used to provide information on the frequency distribution of tree diameter at breast height $(1.3 \mathrm{~m})(\mathrm{DBH})$, an empirical height-diameter relationship is used to estimate the average height per diameter class, and then stand volume can be computed using a tree two-entry volume equation, and the DBH and height [3].

At present, a variety of probability density distribution functions have been used to describe the stand diameter structure, such as normal distribution, lognormal distribution, beta distribution [4], Johnson's SB distribution [5], distribution and Weibull distribution [2,6-13]. These distribution functions have demonstrated their respective advantages under different regional conditions and tree types, among which the Weibull distribution function was characterized by great adaptability and 
flexibility, simple parameter estimation and obvious biological significance of parameters, and has been widely used in the study of stand diameter distribution modelling [14-23]. The methods widely used to estimate Weibull parameter distribution model have included the moment method, maximum likelihood method, percentiles method and nonlinear regression method [20,24-26], in which the application of nonlinear regression method showed its accuracy and stability [27]. In the dynamic prediction of stand diameter distribution, the main methods have been parameter prediction method (PPM) [27-30], parameter recovery method (PRM) [31-33] and generalized linear model [34-36]. However, there are some problems when Weibull is used to fit the diameter distribution data, such as the iterated function of the three-parametric Weibull distribution not being easy to converge, and the correlativity between the parameters estimates and the whole stand characteristics becoming weak $[37,38]$. Thus, we wish to explore a new diameter distribution model that overcomes the disadvantages of Weibull and has the advantages of high simulation precision.

Maximum entropy (MaxEnt) distribution is one of the most active machine learning methods at present. Maximum entropy theory holds that under the action of no external force, the thing with the maximum entropy is the closest to its real state. Maximum entropy statistical modeling selects the distribution with the maximum entropy from the distribution meeting the conditions as the best distribution maximum entropy model. The prominent advantage of the maximum entropy model is that it can fit the complex response variables composed of multiple function types, and it only needs the distribution data of a small sample to achieve an improved simulation effect [39,40]. At present, MaxEnt distribution is mainly applied to macroecological patterns, including spatial distributions of individuals within species, abundance distributions across species, and distributions of metabolic rates, however, some studies also have shown that maximum entropy does not universally succeed in predicting macroecological patterns [41-43].

Additionally, the problem concerning the diameter distribution model is the distribution of diameter, which means to obtain the frequency distribution histogram or frequency distribution curve of diameter. The content corresponds to the maximum information entropy principle in the study of diameter distribution. When different distribution functions are used to describe the diameter distribution, different information entropy will be obtained. Generally, under the constraint condition, the distribution function with the largest information entropy is closest to the actual distribution. Therefore, the maximum entropy principle is suitable for studying diameter distribution.

The objectives of this study were to explore the application of MaxEnt distribution on modeling and prediction of stand diameter distribution and compare the properties of modeling and prediction for stands diameter distribution between MaxEnt distribution and three-parametric Weibull distribution, using the long-term repeated measurement data sets from China fir (Cunninghamia lanceolata) plantations in southern China Guizhou. It is expected to provide a theoretical basis and technical support for better development of Chinese fir plantation management in Guizhou.

\section{Materials and Methods}

\subsection{Data}

Data were obtained from the long-term repeated measurement data sets from China fir plantations in Guizhou Province measured. Each plot area was 0.0667 ha, and the retest covers the sample plot data and sample tree data. The main survey factors of the sample plot data included tree species, origin, average age (AGE), average diameter at breast height $(\mathrm{Dg})$, average tree height $(\mathrm{H})$ and stand density $(\mathrm{N})$; the sample data was the diameter at breast height (DBH) and the volume of individual tree in the corresponding sample plot data. The sample tree was measured after DBH reached $5.0 \mathrm{~cm}$. The diameter classes applied were $2 \mathrm{~cm}$ wide, and the number of trees of each diameter class was counted respectively, calculating the cumulative percentage of each diameter class. Additionally, the coefficient of variation (DBH_CV), skewness (DBH_SKEW) and kurtosis (DBH_KURT) of each plot were calculated. The data consisted of 260 measurements, with a 5-year re-measurement interval, 
obtained in 2005 and 2010. In this study, 130 plots (in 2005) were used in the model development, and another 130 plots (in 2010) for validation. Summary statistics for both data sets are presented in Table 1.

Table 1. Statistics of stand variables.

\begin{tabular}{ccccccccccc}
\hline \multirow{2}{*}{ Variables } & \multicolumn{4}{c}{ Fit Data } & \multicolumn{5}{c}{ Validation Data } \\
\cline { 2 - 11 } & Min & Max & Mean & SD & CV & Min & Max & Mean & SD & CV \\
\hline AGE (years) & 12 & 35 & 18 & 5.32 & 0.2956 & 17 & 39 & 22 & 4.76 & 0.2164 \\
Dg (cm) & 7.3 & 24.2 & 12.5 & 4.11 & 0.3288 & 7.9 & 26 & 14.3 & 4.63 & 0.3238 \\
D (cm) & 7.3 & 23.2 & 12.2 & 3.7 & 0.3033 & 7.8 & 25.9 & 13.6 & 4.25 & 0.3125 \\
H (m) & 4.6 & 19 & 10.2 & 3.51 & 0.3441 & 4.5 & 19 & 10.9 & 3.59 & 0.3294 \\
N (trees·ha-1) & 495 & 3493 & 1414 & 629.41 & 0.4451 & 480 & 3733 & 1440 & 588.02 & 0.4083 \\
\hline
\end{tabular}

Note: $\mathrm{D}$, arithmetic-mean diameter $(\mathrm{cm}) ; \mathrm{SD}$, standard deviation; $\mathrm{CV}$, coefficient of variation.

\subsection{Weibull Distribution of Stand Diameter}

In this study, Weibull distributions with two and three parameters were selected to simulate the diameter distribution of Chinese fir plantation, and the corresponding distribution function forms are shown in Equations (1) and (2).

$$
\begin{gathered}
f(x ; \mathrm{b}, \mathrm{c})=1-\exp \left[-\left(\frac{x}{b}\right)^{c}\right] \\
f(x ; \mathrm{a}, \mathrm{b}, \mathrm{c})=1-\exp \left[-\left(\frac{x-a}{b}\right)^{c}\right]
\end{gathered}
$$

where, $x$ corresponds to the diameter class value of the upper and lower limit intervals of the diameter class; $\mathrm{f}(\mathrm{x})$ corresponds to the cumulative percentage of the number of trees of each diameter class; $\mathrm{a}$ is the location parameter, referring to the downline of the smallest diameter class of the diameter distribution; $\mathrm{b}$ is the scale parameter, $\mathrm{b}>0$; and $\mathrm{c}$ is the shape parameter, $\mathrm{c}>0$.

Based on the distribution function, the formulas of tree number for different diameter classes (3) (4) can be deduced.

$$
\begin{gathered}
n_{i}=N\left\{\exp \left[-\left(\frac{U_{i}}{b}\right)^{c}\right]-\exp \left[-\left(\frac{L_{i}}{b}\right)^{c}\right]\right\} \\
n_{i}=N\left\{\exp \left[-\left(\frac{U_{i}-a}{b}\right)^{c}\right]-\exp \left[-\left(\frac{L_{i}-a}{b}\right)^{c}\right]\right\}
\end{gathered}
$$

where, $n_{i}$ is the number of trees of diameter class $i$ of the stand; $\mathrm{N}$ is the number of trees per unit area of the stand, trees.ha-1; $U_{i}$ and $L_{i}$ are the upper and lower limits of diameter class $i$ of the stand.

Weibull distribution parameter estimation can be solved by a variety of mathematical methods. The nonlinear regression method in SAS software can seek the optimal solution of model parameters through multiple iterations. This method is selected in this study and Marquardt is chosen as the iterative method.

\subsection{MaxEnt Distribution of Stand Diameter}

The maximum entropy principle is applied to the distribution of stand diameter. The maximum entropy model of stand diameter aims to seek the distribution where entropy reaches the maximum value under certain constraint conditions:

$$
\begin{gathered}
\max S(p)=-\sum_{i=1}^{n} p_{i} \ln \left(p_{i}\right) \\
\text { s.t. } \sum_{i=1}^{n} p_{i} d_{i}{ }^{(k)}=d_{k}(\mathrm{k}=1,2,, \mathrm{~m})
\end{gathered}
$$




$$
\sum_{i=1}^{n} p_{i}=1
$$

where $i$ is the order number of diameter class, $k=1,2, \ldots, n ; n$ is the number of diameter classes; $p_{i}$ is the tree number probability in the ith diameter class of stand; $d_{i}$ is the diameter class value in the ith diameter class of stand; $\mathrm{k}$ is the order number of the origin moments of diameter classes, $\mathrm{k}=1,2, \ldots \mathrm{m}$; $\mathrm{m}$ is the number of the origin moment of diameter class, and is also the highest order of the origin moment; $d_{i}{ }^{(k)}$ is the number of trees of diameter class $i$ at origin moment $k$; $d_{k}$ is the expected value of the origin moment $\mathrm{k}, \mathrm{d}_{\mathrm{k}}=\sum_{\mathrm{i}=1}^{\mathrm{n}} \mathrm{p}_{\mathrm{i}} \mathrm{d}_{\mathrm{i}}{ }^{(\mathrm{k})}$.

The central task of the maximum entropy model is to find out the method of determining $\mathrm{p}_{\mathrm{i}}$. Since entropy function $S$ is a concave function, it can be transformed into a convex programming problem with separable variables, according to the duality theory of mathematical programming, and then the global optimal solution of its closed form can be obtained through the standing value condition of the Lagrange function. Under the constraints of Equations (6) and (7), the maximum of Equation (5) is solved by Lagrange multiplier method. First, the left side of Equation (6) is multiplied by $\lambda_{k}$, and the left side of Equation (7) is multiplied by $\lambda-1$, and then these resulting expressions are added. Then the sum is subtracted from Equation (5) to obtain Lagrange function, Equation (8).

$$
\mathrm{L}(\mathrm{p}, \mathrm{u})=-\sum_{\mathrm{i}=1}^{\mathrm{n}} \mathrm{p}_{\mathrm{i}} \ln \left(\mathrm{p}_{\mathrm{i}}\right)-(\lambda-1) \sum_{\mathrm{i}=1}^{\mathrm{n}} \mathrm{p}_{\mathrm{i}}-\sum_{\mathrm{k}=1}^{\mathrm{m}} \lambda_{\mathrm{k}}\left(\sum_{\mathrm{i}=1}^{\mathrm{n}} \mathrm{p}_{\mathrm{i}} \mathrm{d}_{\mathrm{i}}{ }^{(\mathrm{k})}\right)
$$

The first order partial derivative of $\mathrm{p}_{\mathrm{i}}$ is obtained by using Lagrange function Equation (8), and when it is equal to zero, Equation (9), and Equation (10) are obtained. By combining Equations (10), (2) and (3), then Equations (11) and (12) can be obtained. Equation (12) is a system of non-linear equations about $\lambda_{k}$, and the numerical method is used to solve $\lambda_{k}$. Equation (11) is substituted by $\lambda_{k}$ to get $\lambda$, Equation (10) is substituted by $\lambda_{k}$ and $\lambda$ to get $p_{i}$, and Equation (5) is substituted by $p_{i}$ to get $S$, thus completing the task of solving $\mathrm{p}_{\mathrm{i}}$ and $\mathrm{S}$.

$$
\frac{\partial L}{\partial p_{i}}=-1-\ln \left(p_{i}\right)-\lambda+1-\sum_{k=1}^{m} \lambda_{k} d_{i}^{k}=0
$$

where $\lambda$, Lagrange multiplier; $\lambda_{k}$, k-order moment coefficients.

$$
\begin{gathered}
p_{i}=\exp \left(-\lambda-\sum_{i=1}^{n}\left(\lambda_{k} d_{i}^{k}\right)\right) \\
\lambda=\ln \left(\sum_{i=1}^{n} \exp \left(-\sum_{k=1}^{m}\left(\lambda_{k} d_{i}^{k}\right)\right)\right) \\
\sum_{i=1}^{n} \exp \left(-\sum_{k=1}^{m}\left(\lambda_{k} d_{i}^{k}\right)\right) *\left(d_{i}^{k}-d_{k}\right)=0
\end{gathered}
$$

In the problem of determining the value of $\mathrm{m}$, if the value of $\mathrm{m}$ is small, the constraint equations are few and the calculation amount is small, but the constraint conditions described may not be comprehensive enough. If the value of $\mathrm{m}$ is large, there are many constraint equations, and the constraint conditions described are relatively comprehensive, but the computational work is large. When $\mathrm{m}$ is large enough, its contribution to the accuracy of the description model becomes smaller and smaller. Therefore, exploring the value of $\mathrm{m}$ can, not only make the model accurately describe the actual distribution, but also make the calculation amount moderate. Considering that the minimum number of sample diameter class interval in this paper was $6(\mathrm{MIN}$ (sample size) $=6)$, the maximum 
number of model parameters was 5 when fitting. In this paper, the range of $\mathrm{m}$ from 1 to 4 was explored. The diameter distribution model corresponding to $m=1$ to 4 and its parameters are given in Table 2 .

Table 2. Maximum entropy (MaxEnt) model of stand diameter distribution.

\begin{tabular}{lll}
\hline \multicolumn{1}{c}{ m Value } & \multicolumn{1}{c}{ Model } & \multicolumn{1}{c}{ Parameter } \\
\hline$m=1$ & $\mathrm{p}_{\mathrm{i}}=\exp \left(-\lambda-\lambda_{1} \mathrm{~d}_{\mathrm{i}}^{1}\right)$ & $\lambda, \lambda_{1}$ \\
$m=2$ & $\mathrm{p}_{\mathrm{i}}=\exp \left(-\lambda-\lambda_{1} \mathrm{~d}_{\mathrm{i}}^{1}-\lambda_{2} \mathrm{~d}_{\mathrm{i}}^{2}\right)$ & $\lambda, \lambda_{1}, \lambda_{2}$ \\
$m=3$ & $\mathrm{p}_{\mathrm{i}}=\exp \left(-\lambda-\lambda_{1} \mathrm{~d}_{\mathrm{i}}^{1}-\lambda_{2} \mathrm{~d}_{\mathrm{i}}^{2}-\lambda_{3} \mathrm{~d}_{\mathrm{i}}^{3}\right)$ & $\lambda, \lambda_{1}, \lambda_{2}, \lambda_{3}$ \\
$m=4$ & $\mathrm{p}_{\mathrm{i}}=\exp \left(-\lambda-\lambda_{1} \mathrm{~d}_{\mathrm{i}}^{1}-\lambda_{2} \mathrm{~d}_{\mathrm{i}}^{2}-\lambda_{3} \mathrm{~d}_{\mathrm{i}}^{3}-\lambda_{4} \mathrm{~d}_{\mathrm{i}}^{4}\right)$ & $\lambda, \lambda_{1}, \lambda_{2}, \lambda_{3}, \lambda_{4}$ \\
\hline
\end{tabular}

The algorithm flow of solving parameters is as follows: Step1, take $m=3$ as an example, the corresponding MaxEnt model $\mathrm{p}_{\mathrm{i}}=\exp \left(-\lambda-\lambda_{1} \mathrm{~d}_{\mathrm{i}}^{1}-\lambda_{2} \mathrm{~d}_{\mathrm{i}}^{2}-\lambda_{3} \mathrm{~d}_{\mathrm{i}}^{3}\right)$, the model is fitted using SAS PROC MODEL (SAS Institute 2010), the estimates coefficients of each plot are $\lambda, \lambda_{1}, \lambda_{2}$ and $\lambda_{3}$;

Step2, taking $\lambda_{1}, \lambda_{2}, \lambda_{3}$ as initial values, the numerical solution of the system of non-linear Equations (13) are solved, the predicted values of the parameters are $\operatorname{PRE} \lambda_{1}, \operatorname{PRE} \lambda_{2}$ and $\operatorname{PRE} \lambda_{3}$;

$$
\left\{\begin{array}{l}
\sum_{i=1}^{n} \exp \left(-\lambda_{1} d_{i}^{1}-\lambda_{2} d_{i}^{2}-\lambda_{3} d_{i}^{3}\right) *\left(d_{i}^{1}-d_{1}\right)=0 \\
\sum_{i=1}^{n} \exp \left(-\lambda_{1} d_{i}^{1}-\lambda_{2} d_{i}^{2}-\lambda_{3} d_{i}^{3}\right) *\left(d_{i}^{2}-d_{2}\right)=0 \\
\sum_{i=1}^{n} \exp \left(-\lambda_{1} d_{i}^{1}-\lambda_{2} d_{i}^{2}-\lambda_{3} d_{i}^{3}\right) *\left(d_{i}^{3}-d_{3}\right)=0
\end{array}\right.
$$

Step3, substitute PRE $\lambda \mathrm{k}\left(\lambda_{1}, \lambda_{2}\right.$ and $\left.\lambda_{3}\right)$ into Equation (11) to obtain PRE $\lambda$. Step4, substitute PRE $\lambda \mathrm{k}$ and PRE $\lambda$ into Equation (10) to get $p_{i}$ prediction formula.

The obtained parameters are substituted into Equation (10), and the theoretical probability value is obtained. In other words, the theoretical probability distribution is obtained. The diameter distribution model is obtained by Chi-squared test of the theoretical distribution.

\subsection{Dynamic Prediction of Stand Diameter Distribution}

In the dynamic prediction of stand diameter distribution in this paper, the Weibull diameter distribution results were predicted by the PPM and the PRM. The MaxEnt diameter distribution used the PPM and the PSIM to realize the prediction of the unknown stand diameter distribution.

When the PPM was applied, two cases were considered: (1) the regression relationship between the parameters and 8 factors including stand characteristic factor $(t, D, D g, H$ and $N)$ and stand $\mathrm{DBH}$ characteristic factor (DBH_KURT, DBH_SKEW and DBH_CV) was established; (2) the regression relationship between the parameters and 5 stand characteristic factors ( $t, D, D g, H$ and $N)$. By stepwise regression analysis, the parameter prediction model was established.

When the PRM was applied, the following two key parts are implemented: First, with the help of key points on the distribution curve, the recovery equation of model parameters was established. The three parameter recovery equations are shown below:

$$
\left\{\begin{aligned}
0.333= & 1-\exp \left\{-\left[\left(D_{0.333}-a\right) / b\right]^{c}\right\} \\
& D_{I}=b\left(1-\frac{1}{c}\right)^{\frac{1}{c}}+a \\
0.9= & 1-\exp \left\{-\left[\left(D_{0.9}-a\right) / b\right]^{c}\right\}
\end{aligned}\right.
$$

Second, the correlation equation of stand factor and diameter at key points on the distribution curve (recovery model) were established. Relevant studies [44,45] have shown a power function relationship between the diameter of the key points and Dg, so Equation (15) was used to estimate the diameter of key points in this paper. Therefore, the diameter of the key points was calculated by 
using the Equation set (14), and the regression relationship between them and the stand factor was established to form a complete prediction system. If the stand factor is known, the prediction of the diameter distribution of the unknown stand can be realized:

$$
D_{i}=m D_{g}^{n}
$$

where $D_{i}$ refers to the corresponding diameter of the key point $i$, the three key points are $0.333,0.9$ and the longitudinal coordinates of the inflection point of the equation; $D_{0.333} D_{0.9}$ and $D_{I}$ are the diameters corresponding to the key points; $\mathrm{m}$ and $\mathrm{n}$ are the parameters to be estimated.

According to the characteristics of maximum entropy model belonging to the machine learning algorithm, this paper presents a dynamic prediction method of stand diameter distribution by plot similarity index method. The idea is to find a similar sample plot in the fitting data set, match the prediction parameters of the unknown stand diameter distribution, and realize the prediction of the unknown stand diameter distribution. Since skewness and kurtosis can evaluate the shape characteristics of stand diameter distribution, the variation coefficient can indicate the diameter distribution range. Equation (16) was used to calculate the similarity index of two places through these three variables. For each plot in the test data set, put the corresponding value into Equation (16) to calculate the similarity index of plot, and seek the minimum value, and the corresponding plot is the similar plot. In this way, the maximum entropy model parameters of similar plots were used to predict the diameter distribution of stands in the test data:

$$
\mathrm{PSI}=\sqrt{\left(D B H \_K U R T_{F}-D B H \_K U R T_{V}\right)^{2}+\left(\mathrm{DBH} \_S K E W_{F}-\mathrm{DBH} \_S K E W_{V}\right)^{2}+\left(\mathrm{DBH} \_C V_{F}-\mathrm{DBH} \_\mathrm{CV}_{V}\right)^{2}}
$$

where, PSI represents the similarity index of the diameter class distribution of the two plots; DBH_KURT, DBH_SKEW ${ }_{V}$ and $\mathrm{DBH}_{-} \mathrm{CV}_{\mathrm{V}}$ represent the kurtosis, skewness and coefficient of

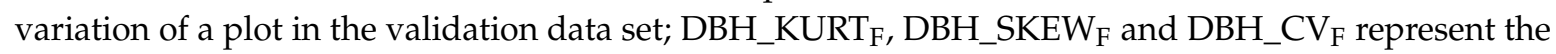
kurtosis, skewness and coefficient of variation of a plot in the fit data set.

\subsection{Comparison of the Models}

The application effect of two-parametric and three-parametric Weibull function was examined by comparing the residual sum of square (RSS) and coefficient of determination $\left(R^{2}\right)$. The results of maximum entropy model fitting were tested by RSS and mean square error (MSE).

$$
\begin{gathered}
R S S=\sum_{i=1}^{n}\left(y_{i}-\hat{y}_{i}\right)^{2} \\
R^{2}=1-\frac{\sum_{i=1}^{n}\left(y_{i}-\hat{y}_{i}\right)^{2}}{\sum_{i=1}^{n}\left(y_{i}-\overline{y_{i}}\right)^{2}} \\
M S E=\frac{1}{n} \sum_{i=1}^{n}\left(y_{i}-\hat{y}_{i}\right)^{2}
\end{gathered}
$$

where, $y_{i}$ is the observed value for the ith observation, $\hat{y}_{i}$ is the predicted value for the ith observation, $\overline{y_{i}}$ is the mean of the $y_{i}$, and $n$ the number of observations in the dataset.

We used the Chi-squared $(\chi 2)[3,6,7,9-11,21-23]$ and Fisher's test as goodness-of-fit measures for the diameter distribution estimations that an estimated distribution corresponds to the real distribution. P-values of less than 0.05 were considered statistically significant. According to the total sample size of each plot ( $\mathrm{n}$ ) and the theoretical number of each diameter class $(\mathrm{T})$, the following three situations can be divided [46]: 
1. When $\mathrm{T} \geq 5$ and $n \geq 40$ then Pearson Chi-square was used.

$$
\chi^{2}=\sum_{j=d \min }^{d \max } \frac{\left(d_{i}-\hat{d}_{i}\right)^{2}}{\hat{d}_{i}}
$$

2. When $\mathrm{T}<5$ but $\mathrm{T} \geq 1$ and $n \geq 40$ then the Chi-square of continuity correction was used.

$$
\chi^{2}=\sum_{j=d \min }^{d \max } \frac{\left(\left|d_{i}-\hat{d}_{i}\right|-0.5\right)^{2}}{\hat{d}_{i}}
$$

3. When $\mathrm{T}<1$ or $\mathrm{n}<40$ then Fisher's test was used.

where, $\mathrm{d}_{\mathrm{i}}$ is the observed diameter class value in the ith diameter class of stand; $\hat{\mathrm{d}}_{\mathrm{i}}$ is the estimated diameter class value in the ith diameter class of stand; in accordance with the reliability $\alpha=0.05$, if $\chi^{2}<\chi_{0.05}^{2}$, the distribution status of the current stand data was consistent with the corresponding distribution function.

Using the Wilcoxon's nonparametric ranked sum (or Mann-Whitney-Wilcoxon, MWW) test, we can decide whether the population distributions are identical without assuming that they follow the normal distribution [47]. It is also an effective goodness-of-fit measure for the diameter distribution estimations. A two-sided probability value of less than 0.05 was considered to be statistically significant. The statistical analysis was performed in SAS PROC NPAR1WAY (SAS Institute 2010).

\section{Results}

\subsection{Modeling Results of MaxEnt Distribution and Weibull distribution}

Table 3 shows the mathematical characteristics of parameters and statistics for MaxEnt distribution and the Weibull distribution derived from the 130 plot measurements. For Weibull distribution, the estimates of parameters were all greater than $1(>0)$, which was identical to the empirical distribution range mentioned in Equations (1) and (2). The small floating range of parameter $a, b$ or $c$ showed that these parameters were both stable. Although the precision of the two models were both high, the three-parametric Weibull distribution presented a more accurate simulation than the two-parametric Weibull function, in view of RSS and $R^{2}$. For the MaxEnt distribution equation, it can be seen from the RSS and MSE that the fitting results of the two-parameter MaxEnt model $(m=1)$ and the three-parameter MaxEnt model $(m=2)$ were poor, and that the fitting results of the four-parameter MaxEnt model $(m=3)$ and five-parameter MaxEnt model $(m=4)$ were good.

Table 3. The mathematical characteristics of parameters and statistics for Weibull distribution and

\begin{tabular}{|c|c|c|c|c|c|c|c|}
\hline \multirow{2}{*}{ Equations } & \multicolumn{3}{|c|}{ The Range of Parameters } & \multicolumn{2}{|c|}{ RSS } & \multicolumn{2}{|l|}{$R^{2}$} \\
\hline & a & b & c & Range & Mean & Range & Mean \\
\hline Weibull (2 parameters) & - & 7.6686-20.7509 & $1.5408-5.0178$ & $0.0001-0.0243$ & 0.0067 & $0.9592-0.9998$ & 0.991 \\
\hline Weibull (3 parameters) & $0.0133-5.4343$ & 2.4871-14.6102 & $0.7116-4.2106$ & $0.0001-0.013$ & 0.0029 & $0.9866-0.9999$ & 0.9962 \\
\hline \multirow{2}{*}{ Equations } & \multicolumn{5}{|c|}{ The range of parameters } & \multirow{2}{*}{ RSS } & \multirow{2}{*}{ MSE } \\
\hline & $\lambda$ & $\lambda 1$ & $\lambda 2$ & $\lambda 3$ & $\lambda 4$ & & \\
\hline MaxEnt $(m=1)$ & $-0.9300-2.9833$ & $-0.0329-0.2929$ & - & - & - & 3.6593 & 0.0031 \\
\hline MaxEnt $(m=2)$ & $-1.6946-18.4703$ & $-2.7981-0.4815$ & $-0.0107-0.1129$ & - & - & 1.2810 & 0.0011 \\
\hline MaxEnt $(m=3)$ & $-43.3154-30.9342$ & $-4.7104-15.2403$ & $-1.6574-0.4722$ & $-0.0142-0.0583$ & - & 0.9135 & 0.0008 \\
\hline MaxEnt $(m=4)$ & $-69.0675-144.4718$ & $-63.0193-27.2593$ & $-3.7168-10.0934$ & $-0.6991-0.2128$ & $-0.0044-0.0177$ & 70.5794 & 0.0005 \\
\hline
\end{tabular}
MaxEnt distribution derived from the 130 plot measurements.

To further evaluate the fitting effect of Weibull distribution and MaxEnt distribution of stand diameter distribution of Chinese fir plantation, the estimated diameter distributions were compared 
with the observed diameter distributions using $\chi 2+$ Fisher's test $(p=0.05)$ and MWW test in Table 4 . MWW test showed the four equal acceptance rate $100 \%$, which roughly concluded that the observed and estimated diameter class values of each sample plot were not significantly different, and their population distributions were identical without assuming that they followed the normal distribution. As for $\chi^{2}+$ Fisher's test, results indicated that the acceptance rate of the four distribution equations reached $90 \%$, which showed that the simulated stand diameter distribution of Chinese fir plantation was good, and that the MaxEnt distribution was better than the Weibull distribution. The three-parameter Weibull distribution was slightly better than the two-parameter weibull distribution. In the MaxEnt distribution, the four-parameter $(m=3)$ and five-parameter $(m=4)$ had the same highest acceptance rate $(95.38 \%)$. Under the same acceptance rate, a four-parameter maximum entropy distribution model with few parameters was selected.

Table 4. Acceptance statistic of Weibull distribution and MaxEnt distribution of fitted results for 130 plots.

\begin{tabular}{cccc}
\hline Equations & Total Number & $\begin{array}{c}\text { X2 + Fisher's Test } \\
\text { Acceptance (\%) }\end{array}$ & $\begin{array}{c}\text { MWW Test } \\
\text { Acceptance (\%) }\end{array}$ \\
\hline Weibull (2 parameters) & 130 & $90.00 \%$ & $100 \%$ \\
Weibull (3 parameters) & 130 & $92.31 \%$ & $100 \%$ \\
MaxEnt $(m=3)$ & 130 & $95.38 \%$ & $100 \%$ \\
MaxEnt $(m=4)$ & 130 & $95.38 \%$ & $100 \%$ \\
\hline
\end{tabular}

\subsection{Analysis of Dynamic Prediction Results of Stand Diameter}

\subsubsection{Weibull Distribution Prediction Effect of PPM and PRM}

Analyzing the relationship between parameters a, b, c and stand factors, the relevant literature [46] has shown that the Pearson coefficient is more convincing when measuring the linear correlation between variables, while the Spearman coefficient is typically used to measure the non-linear correlation between variables. Table 5 shows the Pearson correlation coefficient and the Spearman correlation coefficient of three parameters Weibull and stand factors. Results indicate that parameter $a$ had a significant correlation with stand density (N), skewness (DBH_SKEW) and the coefficient of variation (DBH_CV), and the linear relationship of $\mathrm{N}$ was greater than the non-linear relationship. The parameter $b$ was highly correlated with stand age (AGE), average diameter at breast height (Dg), arithmetic mean diameter $(\mathrm{D})$ and stand average height $(\mathrm{H})$, and the nonlinear correlation with $\mathrm{Dg}$ and $\mathrm{D}$ reached more than $80 \%$. The correlation between parameter $c$ and stand density $\mathrm{N}$ was not significant at 0.05 level, but significant for other stand factors.

Table 5. Pearson correlation coefficient and Spearman correlation coefficient between parameters and stand factors.

\begin{tabular}{|c|c|c|c|c|c|c|c|c|c|}
\hline \multirow{2}{*}{ Parameters } & \multirow{2}{*}{ Correlation } & \multicolumn{8}{|c|}{ Stand Factors } \\
\hline & & AGE & $\mathrm{D}_{\mathrm{g}}$ & $\mathbf{H}$ & $\mathbf{N}$ & P_DBH & DBH_KURT & DBH_SKEW & DBH_CV \\
\hline \multirow{2}{*}{ a } & Pearson & -0.07289 & -0.18313 & -0.20914 & $-0.4309^{* * *}$ & -0.01966 & 0.2400 & 0.3599 ** & 0.3102 * \\
\hline & Spearman & -0.0727 & -0.2524 & -0.1916 & $-0.4215^{* *}$ & -0.1146 & 0.2422 & 0.3640 ** & 0.3282 * \\
\hline \multirow{2}{*}{ b } & Pearson & $0.4073^{* *}$ & $0.7894^{* * *}$ & $0.7521^{* * *}$ & 0.12525 & $0.8441^{* * *}$ & $-0.3430 * *$ & $-0.5225^{* * *}$ & $-0.3997 * *$ \\
\hline & Spearman & $0.3711^{* *}$ & $0.8207^{* * *}$ & $0.7222 * * *$ & 0.1411 & $0.8688^{* * *}$ & -0.2306 & $-0.5180^{* * *}$ & $-0.4159 * *$ \\
\hline \multirow[b]{2}{*}{ c } & Pearson & 0.0596 & 0.3865 ** & $0.4539 * * *$ & $0.3752 * *$ & $0.4026^{* *}$ & -0.2992 * & $-0.5849^{* * *}$ & $-0.7369^{* * *}$ \\
\hline & Spearman & 0.0588 & $0.4766^{* * *}$ & $0.4396^{* * *}$ & $0.3685^{* *}$ & $0.4648^{* * *}$ & -0.2748 * & $-0.6286^{* * *}$ & $-0.7569 * * *$ \\
\hline
\end{tabular}

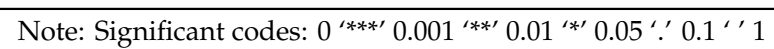

In combination with the above correlation analysis, the power function and logarithm form were used to represent the nonlinear relationship. Taking the complexity (number of variables) and accuracy of the equation into consideration, the parametric prediction model of the Weibull distribution equation with three parameters was obtained by stepwise regression analysis, as shown in Table 6. On the whole, 
the parameter prediction method with 8 factors was better than that with 5 factors, mainly because there were many stand factors used in the parameter prediction, and $R^{2}$ of the parameter prediction model was larger. However, considering that some of the 8 factors were not easy to master for the unknown stands, the prediction model of 5 factors, which was key to stand growth and commonly used, was selected here, and the prediction effect was good.

Table 6. Parametric prediction models and their prediction effects.

\begin{tabular}{clcc}
\hline Factor & \multicolumn{1}{c}{ Parametric Prediction Model } & $\boldsymbol{R}^{2}$ & Number \\
\hline \multirow{5}{*}{8 factors } & $\hat{\mathrm{a}}=-0.00067174 * \mathrm{~N}-0.5642 * \mathrm{D}_{\mathrm{KURT}}+1.47489 * 3.765416 * \mathrm{D}_{\mathrm{KURT}} 0.105997+\varepsilon$ & 0.9236 & $\mathrm{~A}$ \\
& $\hat{\mathrm{b}}=0.86528 * 0.185573 \mathrm{D}^{1.54466}-0.68411 * \ln \left(\mathrm{D}_{\mathrm{KURT}}\right)+\varepsilon$ & 0.9688 & $\mathrm{~B}$ \\
& $\hat{\mathrm{c}}=-0.09176 * \mathrm{D}_{\mathrm{CV}}+1.14257 * \ln \left(\mathrm{D}_{\mathrm{g}}\right)+0.32042 \ln (\mathrm{N})+\varepsilon$ & 0.9505 & $\mathrm{C}$ \\
\hline \multirow{3}{*}{5 factors } & $\hat{\mathrm{a}}=-0.39343 * \mathrm{D}_{\mathrm{g}}-0.00115 * \mathrm{~N}+4.42011 * \ln (\mathrm{D})+\varepsilon$ & 0.8885 & $\mathrm{D}$ \\
& $\hat{\mathrm{b}}=0.00306 * \mathrm{~N}+0.68681 * 0.185573 * \mathrm{D} * 1.544666+6.39048 * \ln \left(\mathrm{D}_{\mathrm{g}}\right)-2.6553 * \ln (\mathrm{N})+\varepsilon$ & 0.9755 & $\mathrm{E}$ \\
& $\hat{\mathrm{c}}=0.10801 * \mathrm{D}_{\mathrm{g}}+0.000692 * \mathrm{~N}-1.20507 * \ln (\mathrm{AGE})+1.24915 * \ln (\mathrm{D})+\varepsilon$ & 0.9201 & $\mathrm{~F}$ \\
\hline
\end{tabular}

Notes: 8 factors, Stand Characteristic Factor and Stand DBH Characteristic Factor; 5 factors, Stand Characteristic Factor.

Table 7 shows the recovery model and its prediction effect between the diameter and Dg of the three key points. The results show that the recovery model at the key points of 0.333 and 0.9 had good prediction effect, while the prediction effect at the inflection point was slightly worse. Simultaneous parameter recovery equations were established, and the predicted values of Weibull parameters $a, b$ and c were obtained by solve function in MATLAB.

Table 7. Recovery equations and their prediction effects.

\begin{tabular}{cccc}
\hline Diameter at Key Point & Recovery Equation & $\boldsymbol{R}^{2}$ & Number \\
\hline $\boldsymbol{D}_{0.333}$ & $\hat{D}_{0.333}=1.2617 * D_{g}^{0.7807}$ & 0.7415 & $\mathrm{G}$ \\
$\boldsymbol{D}_{\boldsymbol{I}}$ & $\hat{D}_{I}=0.9570 * D_{g}^{0.8961}$ & 0.4988 & $\mathrm{H}$ \\
$\boldsymbol{D}_{\mathbf{0 . 9}}$ & $\hat{D}_{0.9}=1.0434 * D_{g}^{1.0802}$ & 0.8756 & $\mathrm{I}$ \\
\hline
\end{tabular}

\subsubsection{MaxEnt Distribution Prediction Effect of PPM and PSIM}

The relationship between the MaxEnt model parameters and each stand factor was analyzed. Table 8 showed the Pearson correlation coefficient and Spearman correlation coefficient of the four-parameter MaxEnt model parameters and the stand factor. Four parameters $(\lambda, \lambda 1, \lambda 2$ and $\lambda 3$ ) had a relatively weak correlation with forest stand factors, parameter $\lambda$ was significantly correlated with $\mathrm{H}$ and DBH_CV, parameter $\lambda 1$ was correlated in a non-linear way with variation coefficient DBH_CV at 0.1 level, parameter $\lambda 2$ was non-linear and positive with DBH_KURT and DBH_SKEW at 0.1 level, and parameter $\lambda 3$ had a negative nonlinear correlation with DBH_KURT and DBH_SKEW at 0.1 level. Through stepwise regression analysis, the parametric prediction models of the four-parameter MaxEnt distribution equations were obtained respectively, as shown in Table 9. Results indicated that the fitting effect of the MaxEnt distribution parameter prediction model considering 8 factors was worse than that of the 5 factors, and the 8 factors prediction model, which was a little better, was selected in this study. 
Table 8. Pearson correlation coefficient and Spearman correlation coefficient between parameters and stand factors.

\begin{tabular}{|c|c|c|c|c|c|c|c|c|c|}
\hline \multirow{2}{*}{ Parameters } & \multirow{2}{*}{ Correlation } & \multicolumn{8}{|c|}{ Stand Factors } \\
\hline & & AGE & DВНОВ & THGT & D_N & P_DBH & DBH_KURT & DBH_SKEW & DBH_CV \\
\hline \multirow{2}{*}{$\lambda$} & Pearson & -0.0487 & 0.1636 & 0.1755 * & 0.0678 & 0.1400 & 0.0556 & -0.0418 & $-0.2257^{* *}$ \\
\hline & Spearman & -0.1068 & 0.1283 & 0.1782 * & 0.0552 & 0.0544 & 0.1114 & -0.0382 & $-0.3216^{* * *}$ \\
\hline \multirow{2}{*}{$\lambda 1$} & Pearson & 0.0711 & -0.1061 & -0.1013 & -0.0600 & -0.0445 & -0.0790 & -0.0445 & 0.1127 \\
\hline & Spearman & 0.1225 & -0.0029 & -0.0511 & -0.0263 & 0.0848 & -0.1448 & -0.1064 & 0.1645 \\
\hline \multirow{2}{*}{$\lambda 2$} & Pearson & -0.0563 & 0.1062 & 0.0848 & 0.0367 & 0.0413 & 0.0864 & 0.0827 & -0.0308 \\
\hline & Spearman & -0.1163 & -0.0317 & -0.0113 & -0.0277 & -0.1192 & 0.1519 . & 0.1663. & -0.0500 \\
\hline \multirow{2}{*}{$\lambda 3$} & Pearson & 0.0260 & -0.1370 & -0.1015 & -0.0159 & -0.0855 & -0.0782 & -0.0827 & -0.0132 \\
\hline & Spearman & 0.0805 & 0.0209 & 0.0343 & 0.0885 & 0.1027 & -0.1577 & $-0.2079^{*}$ & -0.0398 \\
\hline
\end{tabular}

Note: Significant codes: $0^{\star * * * \prime} 0.001^{\text {*** }} 0.01^{\star * \prime} 0.05^{\prime \prime} 0.1^{\prime \prime} 1$

Table 9. Parametric prediction models and their prediction effects.

\begin{tabular}{|c|c|c|c|}
\hline Factor & Parametric Prediction Model & $R^{2}$ & Number \\
\hline 8 factors & $\begin{array}{l}\hat{\lambda}=0.63419 * \mathrm{D}_{\mathrm{g}}-0.16079 * D B H \_C V+\varepsilon \\
\hat{\lambda_{1}}=0.41956 * \cos (A G E)+0.36605 * \sin (A G E)+0.4716 * \sin (T H G T)-0.45175 * \sin \left(D B H \_K U R T\right)+\varepsilon \\
\hat{\lambda_{2}}=-2.9 \mathrm{E}-05 * \mathrm{~N}-0.03831 * \cos (A G E)-0.03067 * \sin (A G E)-0.04325 * \sin (T H G T)+0.05867 * \sin \left(D B H \_S K E W\right)+\varepsilon \\
\hat{\lambda_{3}}=1.01 \mathrm{E}-06 * \mathrm{~N}+0.02158 * D B H_{S K E W}-0.00093 * \cos (T H G T)+0.00179 * \sin \left(\mathrm{D}_{\mathrm{g}}\right)-0.0478 * \sin \left(D B H \_S K E W\right)+\varepsilon\end{array}$ & $\begin{array}{l}0.3779 \\
0.1679 \\
0.1450 \\
0.1676\end{array}$ & $\begin{array}{l}\text { J } \\
\text { K } \\
\mathrm{L} \\
\mathrm{M}\end{array}$ \\
\hline 5 factors & $\begin{array}{l}\hat{\lambda}=0.20106 * \text { THGT }+\varepsilon \\
\hat{\lambda_{1}}=0.00011397 * N-0.53401 * \cos (T H G T)+0.56427 * \sin (D B H O B)+0.23477 * \sin (D)+\varepsilon \\
\hat{\lambda_{2}}=-2.9 \mathrm{E}-05 * \mathrm{~N}-0.03831 * \cos (A G E)-0.03067 * \sin (A G E)-0.04325 * \sin (T H G T)+0.05867 * \sin \left(D B H \_S K E W\right)+\varepsilon \\
\hat{\lambda_{3}}=1.01 \mathrm{E}-06 * \mathrm{~N}+0.02158 * D B H_{S K E W}-0.00093 * \cos (T H G T)+0.00179 * \sin \left(\mathrm{D}_{\mathrm{g}}\right)-0.0478 * \sin \left(D B H \_S K E W\right)+\varepsilon\end{array}$ & $\begin{array}{l}0.1599 \\
0.0571 \\
0.0914 \\
0.1389\end{array}$ & $\begin{array}{l}\mathrm{N} \\
\mathrm{O} \\
\mathrm{P} \\
\mathrm{Q}\end{array}$ \\
\hline
\end{tabular}

Notes: 8 factors, Stand Characteristic Factor and Stand DBH Characteristic Factor; 5 factors, Stand Characteristic Factor 
The dynamic prediction of diameter distribution of MaxEnt stand based on sample plot similarity index method was encapsulated into a macro program in SAS according to its algorithm example (SAS code in Appendix A). Input is the unknown sample plot data which needs to be predicted, and the output is the predicted values of MaxEnt model parameters $(\lambda, \lambda 1, \lambda 2$ and $\lambda 3)$.

\subsubsection{Comparison of Dynamic Prediction Results of Weibull Distribution and MaxEnt Distribution}

It was encouraging that MaxEnt distribution was found to have lower RSS and higher acceptance rate than the three-parametric Weibull function (e.g., Tables 3 and 4). Data from 130 evaluation subplots provide an opportunity to further analyze and compare the accuracy of the MaxEnt distribution and three-parametric Weibull function. In these calculations, two parameter estimation methods (PPM and PRM) of three-parametric Weibull model and two parameter estimation methods (PPM and PSIM) of four-parameter MaxEnt model were used. The MWW test results for PRM in MaxEnt distribution had a $9.23 \%$ acceptance rate, suggesting significant differences between theoretical values and observed values, which come from different populations. Three other dynamic prediction models from the Weibull and MaxEnt distribution showed the population distributions were identical. The acceptance rate of $\chi 2+$ Fisher's test for PPM and PRM in Weibull distribution was 53.85\% and 26.09\%, respectively, and the acceptance rate of $\chi 2$ + Fisher's test for PPM and PSIM in MaxEnt distribution was 20.77\% and $51.54 \%$, respectively. Overall, for the three-parametric Weibull function, the precision of PPM is far higher than PRM in view of the total $R^{2}$ (Table 10). The four-parameter MaxEnt distribution from PSIM both have provided a good fit for all the stands analyzed, and the four-parameter MaxEnt distribution from PPM provided a relatively bad fit.

Table 10. The statistics of different evaluation methods for MaxEnt distribution and the three-parametric Weibull function derived from the 130 stands used for goodness-of-fit tests.

\begin{tabular}{|c|c|c|c|c|c|}
\hline Equations & Modeling Prediction & Related Equations & Total Number & $\begin{array}{l}\chi 2+\text { Fisher's Test } \\
\text { Acceptance }(\%)\end{array}$ & $\begin{array}{l}\text { MWW test } \\
\text { Acceptance (\%) }\end{array}$ \\
\hline $\begin{array}{l}\text { Weibull (3 } \\
\text { parameters) }\end{array}$ & PPM & $\mathrm{D}, \mathrm{E}, \mathrm{F}$ & 130 & $53.85 \%$ & $98.46 \%$ \\
\hline \multirow{2}{*}{ MaxEnt $(m=3)$} & PPM & $\mathrm{J}, \mathrm{K}, \mathrm{L}, \mathrm{M}$ & 130 & $20.77 \%$ & $9.23 \%$ \\
\hline & PSIM & Appendix A & 130 & $51.54 \%$ & $100 \%$ \\
\hline
\end{tabular}

Figure 1 shows both the actual data distribution (histogram), the estimated MaxEnt distribution shapes from PPM (purple dashed line) and PSIM (purple solid line), the estimated Weibull distribution obtained from PPM (blue solid line) and PRM (blue dashed line) for a selection of stands from different planting densities, stand ages and quadratic mean DBH. In general, MaxEnt distribution from PSIM and Weibull distribution from PPM both provided a good fit for all the stands analyzed, and MaxEnt distribution from PPM provided a relatively bad fit. In comparison, MaxEnt distribution from PSIM is more stable than Weibull distribution from PPM, which can be seen from the application of the two distributions to stand A-F. 

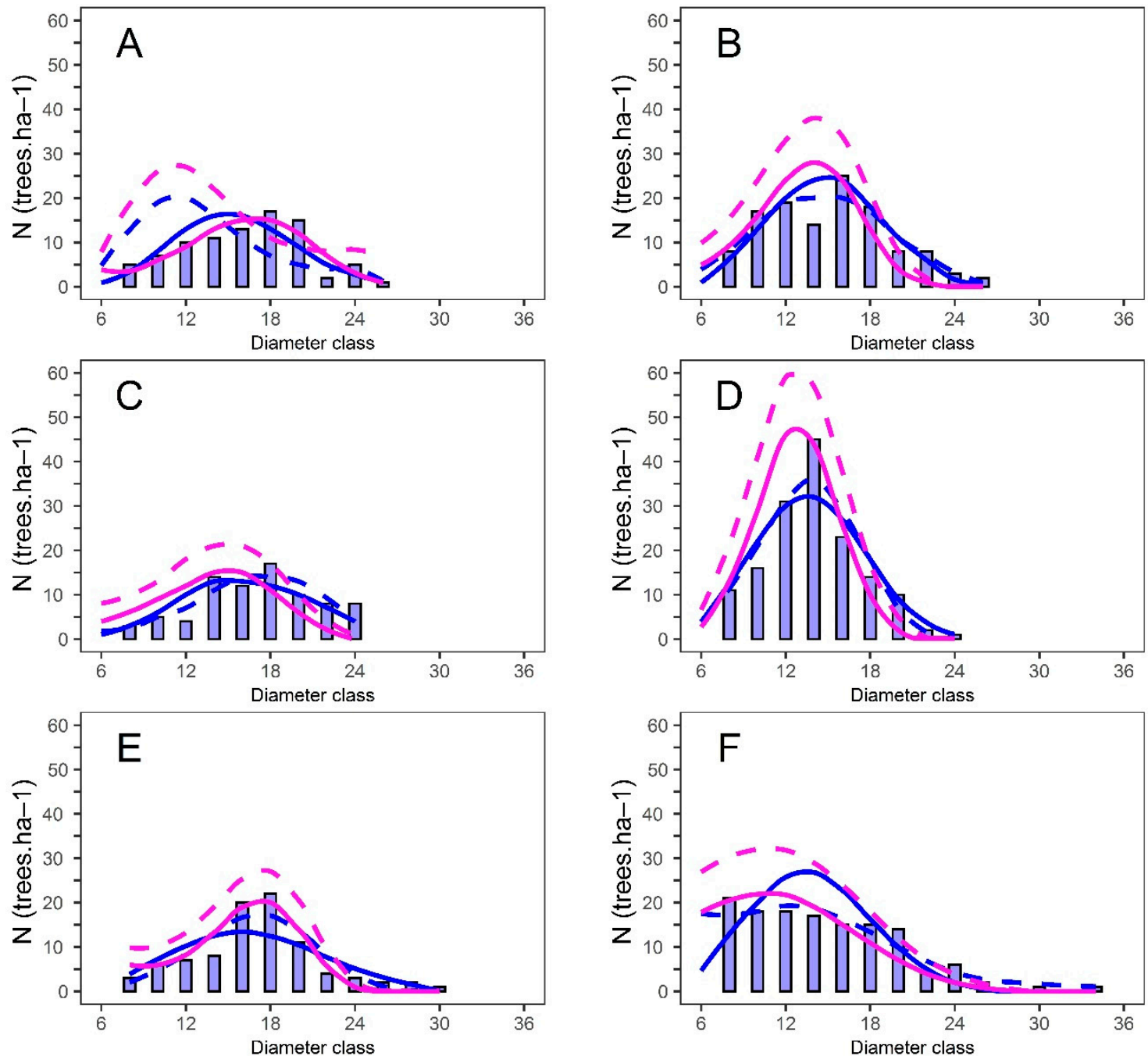

Figure 1. Examples of dynamic prediction of stand diameter distributions. The histograms are the observed is distribution. The MaxEnt distribution (purple dashed line), Weibull distribution obtained from parameter prediction method (PPM) (blue solid line), Weibull distribution obtained from PRM (blue dashed line) and MaxEnt distribution obtained from plot similarity index method (PSIM) (purple dashed line). The information of the six given stands (A-F) include planting density, stand age and quadratic mean DBH in sequence. (A: 1364 stems/ha, 17 a, $16.5 \mathrm{~cm}$; B: 2264 stems/ha, 17 a, $16.0 \mathrm{~cm}$; C: 1244 stems/ha, 22a, $17.3 \mathrm{~cm}$; D: 2384 stems/ha, 21a, $14.2 \mathrm{~cm}$; E: 1349 stems/ha, 27 a, $16.2 \mathrm{~cm}$; F: 2249 stems/ha, 26, 15.2cm).

Considering that the sample-PSIM relies on the sample size of the fitted data set, the larger the sample size is, the more accurate the prediction of PSIM is. Therefore, the PSIM of MaxEnt distribution has great application prospects in the dynamic prediction system of stand diameter distribution.

\section{Discussion}

In the study of stand diameter structure, the probability density function method has played an important role in combination with the general rule of stand diameter structure (the number of trees with medium size accounts for the majority, and the number of trees gradually decreases to the diameter class at both ends). Among the various probability density functions, the most widely used are the normal distribution, Gamma distribution and Weibull distribution. Mathematicians $[48,49]$ obtained several famous typical distributions in statistics from some common constraints, such as Gaussian distribution (Normal distribution), Gamma distribution and Exponential distribution, and proved that 
these common distributions in nature are actually special cases of maximum entropy principle. Jaynes proved mathematically that the probability of the maximum entropy prediction is the predominance in all the predictions of random events [49-51]. In the physical sense, the maximum entropy principle reveals the internal rules of the information system. From the perspective of mathematical model, the maximum entropy principle takes the statistical moment of each diameter class of known data as the constraint condition to describe the distribution of small sample of diameter structure. Therefore, the maximum entropy principle has a very broad application prospect in the simulation of stand diameter distribution.

In practice, the future values of the probability distribution parameters for the diameter distribution is determined or estimated from stand characteristics (e.g., density, age, and mean tree size). In the study of dynamic prediction of stand diameter structure based on probability distribution, two main methods of PPM and PRM have been applied for predicting these parameters in different tree species and forest types over the last 45 years [18,52]. However, when the correlation between parameter estimation and the whole stand characteristics was weak, the accuracy of dynamic prediction of stand diameter distribution by these two methods was not high. Machine learning algorithm can well simulate nonlinear relations, and has the characteristics of fault tolerance, self-learning and self-adaptability, so it has obvious advantages in prediction accuracy. In this research area, artificial neural network(ANN)models have been considered as an alternative to traditional tree diameter Weibull distribution models [53-58]. In this research, MaxEnt which can be regarded as a probability distribution optimization algorithm, has been shown to have potential for solving problems requiring strong nonlinear modeling ability. Compared with PPM, PSIM also has higher prediction accuracy in dynamic prediction of stand diameter distribution.

\section{Conclusions}

Based on analysis of the disadvantages of the Weibull function, this study develops a promising distribution function (MaxEnt distribution), which is a new and essential exploration in the study of parametric methods. We conclude that: (1) MaxEnt distribution $\left(R^{2}=0.9538\right)$ has a more accurate simulation than the three-parametric Weibull function $\left(R^{2}=0.9231\right)$ while modeling diameter distributions of Chinese fir plantations; (2) the goodness-of-fit test showed the diameter distributions of unknown stands can be accurately estimated by applying four-parameter MaxEnt distribution and with regards to modeling precision and theoretical interpretation, PSIM (Table 10) may be the most suitable choice due to its good convergence, high precision; (3) with the increase of the fitted sample size, the more accurate the prediction of MaxEnt distribution PSIM is, it has a great application prospect in the dynamic prediction system of stand diameter distribution.

Author Contributions: Conceptualization, Y.C.; methodology, Y.C.; software, Y.C.; validation, Y.C. and B.W.; formal analysis, Y.C.; investigation, Y.C., B.W. and Z.M.; resources, Y.C., B.W. and Z.M.; data curation, Y.C.; writing - original draft preparation, Y.C.; writing—review and editing, Y.C. and Z.M.; visualization, Y.C.; supervision, B.W.; project administration, B.W.; funding acquisition, B.W.

Funding: This research was funded by the Key National Research and Development Program of China, grant number 2017YFD0600906.

Acknowledgments: We are grateful to Guizhou Forestry Department and Guizhou Forestry Investigation and Planning Institute for supplying valuable modeling data.

Conflicts of Interest: The authors declare no conflict of interest.

\section{Appendix A}

The plot similarity index method (PSIM) example of the SAS code used to validate the MaxEnt model for China fir. DBH.P6 is fitting data, DBH.P7 is validation data. Lines (1) to (20) are used to process raw data sets, adding the serial number ID. Lines (21) to (28) simulate the four-parameter MaxEnt model by fitting data sets, saving parameter information in DBH.MAXENT_fit. Lines (29) to 
(76) use macro to find the most similar sample plot for each sample plot in the validation set, and obtain the parameter prediction values and save them in DBH.MAXENT_P.

(1) PROC SQL

(2) CREATE TABLE DBH.Maxent_6 AS

(3) SELECT DISTINCT PLOT, DBH_KURT, DBH_SKEW, DBH_CV

(4) FROM DBH.P6

(5) ORDER BY PLOT

(6) RUN

(7) DATA DBH.Maxent_6P

(8) SET DBH.Maxent_6

(9) ID = _ $\mathrm{N}_{-}$

(10) RUN

(11) PROC SQL

(12) CREATE TABLE DBH.Maxent_7 AS

(13) SELECT DISTINCT PLOT AS PLOT7, DBH_KURT AS DBH_KURT7, DBH_SKEW AS DBH_SKEW7, DBH_CV AS DBH_CV7

(14) FROM DBH.P7

(15) order by plot

(16) RUN

(17) DATA DBH.Maxent_7P

(18) SET DBH.Maxent_7

(19) $\quad$ ID $=\_N_{-}$

(20) RUN

(21) ODS OUTPUT ResidSummary = DBH.REIDS3_fit

(22) PROC MODEL DATA=DBH. P6 CONVERGE $=0.000001$ METHOD $=$ MARQUARDT

(23) $\mathrm{Pi}=\operatorname{EXP}\left(-\mathrm{b} 0-\mathrm{b} 1^{*} \mathrm{di}-\mathrm{b} 2^{*} \mathrm{di}^{* *} 2-\mathrm{b} 3^{*} \mathrm{di}^{* * 3}\right)$

(24) FIT Pi /OLS OUTEST $=$ DBH. MAXENT_fit OUT $=$ DBH.MAXENT_RESIDUAL3

(25) BY PLot

(26) RUN

(27) QUIT

(28) ODS OUTPUT CLOSE

(29) DATA DBH.MAXENT_P

(30) STOP

(31) RUN

(32) $\%$ let $n=130$

(33) \%MACRO PSI ()

(34) $\%$ do $i=1 \%$ to \&n

(35) proc sql

(36) create table DBH.MAXENT_P7Ai as

(37) select*

(38) from DBH.MAXENT_7P

(39) where ID7 = \& i

(40) run

(41) data DBH.MAXENTp67

(42) MERGE DBH.MAXENT_6P DBH.MAXENT_P7Ai

(43) run

(44) data DBH.MAXENTp67a 
(45) set DBH.MAXENTp67

(46) retain ID1 TIME1 PLOT1 DBH_KURT1 DBH_SKEW1 DBH_CV1 AGE1

(47) if ID7 $^{\wedge}=$. then ID1 = ID7

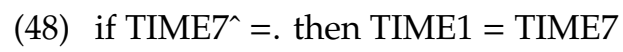

(49) if PLOT7 $^{\wedge}=$. then PLOT1 $=$ PLOT7

(50) if DBH_KURT7^ ${ }^{\wedge}$. then DBH_KURT1 = DBH_KURT7

(51) if DBH_SKEW7^ $=$. then DBH_SKEW1 = DBH_SKEW7

(52) if DBH_CV7^ $=$. then DBH_CV1 = DBH_CV7

(53) if AGE7 $^{\wedge}=$. then AGE1 = AGE7

(54) keep ID TIME PLOT DBH_KURT DBH_SKEW DBH_CV ID1 TIME1 PLOT1 DBH_KURT1 DBH_SKEW1 DBH_CV1

(55) run

(56) data DBH.MAXENTp67b

(57) set DBH.MAXENTp67a

(58) PSI $=$ SQRT $\left((\right.$ DBH_KURT-DBH_KURT1 $) * * 2+($ DBH_SKEW-DBH_SKEW1 $) * * 2+\left(D B H \_C V-\right.$ DBH_CV1) $\left.{ }^{* *} 2\right)$

(59) RUN

(60) proc sql

(61) create table DBH.MAXENTp67C as

(62) select*, MIN(PSI) AS MIN_PSI

(63) from DBH.MAXENTp67b

(64) run

(65) proc sql

(66) create table DBH.MAXENTp67d as

(67) select*

(68) from DBH.MAXENTp67c

(69) where PSI = MIN_PSI

(70) run

(71) data DBH.MAXENT_P

(72) set DBH.MAXENT_P DBH.MAXENTp67d

(73) run

(74) $\%$ end

(75) \% MEND PSI

(76) \% PSI ()

\section{References}

1. Zhang, J.; Duan, A.; Tong, S. An outline of studies on modeling and prediction of stand diameter structure. For. Res. 2004, 17, 787-795.

2. Sheykholeslami, A.; Pasha, K.; Lashaki, K. A study of tree distribution in diameter classes in natural forests of Iran (case study: Liresara forest). Ann. Biol. Res. 2011, 2, 283-290.

3. Dong, C. Study on Morphology and Yield Models for Chinese Fir (Cunninghamia lanceolata) Planted Forests in Fujian Province; Beijing Forestry University: Beijing, China, 2015.

4. Gorgoso-Varela, J.J.; Rojo-Alboreca, A.; Afif-Khouri, E.; Barrio-Anta, M. Modelling diameter distributions of birch (Betula alba L.) and pedunculate oak (Quercus robur L.) stands in northwest Spain with the beta distribution. For. Syst. 2008, 17, 271-281. [CrossRef]

5. Wang, M.; Rennolls, K. Tree diameter distribution modelling: Introducing the logit logistic distribution. Can. J. For. Res. 2005, 35, 1305-1313. [CrossRef]

6. Wang, M.; Sun, D. Logistic Distribution Prediction of Stand Diameter Structure. For. Res. 1998, 11, 537-541. 
7. Wang, P. Study on the Diameter Distribution of Pinus massoniana mixture plantation. Jiangxi For. Sci. Technol. 2005, 5, 6-7.

8. Ma, F.; Jia, L. Advances in the Researches of Stand Growth and Yield Model. World For. Res. 2008, 21, $21-27$.

9. Feng, Y. Study on Diameter Structure Regularity on Masson Pine Plantation in Southern Fujian Mountain. For. Investig. Des. 2010, 2, 4-7.

10. Zhang, J. Study on Diameter Structure Regularity on Masson Pine Plantation in Northern Fujian Mountain. Agrofor. Sci. Technol. Qinghai 2014, 4, 20-22.

11. Hao, W.; Chen, L.; Mei, G. Effects of slope aspect on diameter distribution of Chinese fir (Cunninghamia lanceolata) plantations. J. Northwest A F Univ. (Nat. Sci. Ed) 2016, 44, 61-69.

12. Lima, R.B.; Bufalino, L.; Alves Junior, F.T.; Da Silva, J.A.; Ferreira, R.L. Diameter distribution in a Brazilian tropical dry forest domain: Predictions for the stand and species. Anais da Academia Brasileira de Ciências 2017, 89, 1189-1203. [CrossRef] [PubMed]

13. Mayrinck, R.C.; Filho, A.C.F.; Ribeiro, A.; de Oliveira, X.M.; Lima, R.R.D. A comparison of diameter distribution models for Khaya ivorensis, A. Chev. plantations in Brazil. South. For. A J. For. Sci. 2018, 80, 373-380.

14. Bailey, R.L.; Dell, T.R. Quantifying diameter distributions with the Weibull function. For. Sci. 1973, 19, 97-104.

15. Meng, X. A Study of the Relation Between D and H-Distributions by Using the Weibull Function. J. Beijing For. Univ. 1988, 10, 40-48.

16. Yang, J.; Jiang, X.; Xu, H.; Wang, S.; Yin, G. Diameter Distribution Yield Model of Pinus massoniana Plantation and Its Application. For. Res. 2003, 16, 581-587.

17. Zhang, W.; Gao, T. Study on Diameter Structure of Pinus massoniana. Sichuan For. Surv. Des. 2001, 2, 26-30.

18. Liu, C.; Zhang, S.Y.; Lei, Y.; Newton, P.F.; Zhang, L. Evaluation of three methods for predicting diameter distributions of black spruce (Picea mariana) plantations in central Canada. Can. J. For. Res. 2004, 34, 2424-2432. [CrossRef]

19. Newton, P.F.; Lei, Y.; Zhang, S.Y. Stand-level diameter distribution yield model for black spruce plantations. For. Ecol. Manag. 2005, 209, 181-192. [CrossRef]

20. Lei, Y. Evaluation of three methods for estimating the Weibull distribution parameters of Chinese pine (Pinus tabulaeformis). J. For. Sci. 2008, 54, 566-571. [CrossRef]

21. Gong, Z.-W.; Kang, X.-G.; Gu, L.; Cai, S. The application of WEIBULL distribution function in stand diameter growth and mortality. In Proceedings of the 2010 International Conference on Computer Application and System Modeling (ICCASM 2010), Taiyuan, China, 22-24 October 2010.

22. Chen, C.; Liu, G. Study on weibull function in diameter distribution of Chinese fir plantation. J. Green Sci. Technol. 2017, 3, 59 .

23. Zuo, S. Study on diameter distribution and growth law of Chinese fir in Hunan. East China For. Manag. 2017, 31, 62-64.

24. Fang, Z. Weibull Distribution and the Methods of Its Parameter Estimation. For. Res. 1993, 4, 423-430.

25. Poudel, K.P.; Cao, Q.V. Evaluation of Methods to Predict Weibull Parameters for Characterizing Diameter Distributions. For. Sci. 2013, 59, 243-252. [CrossRef]

26. Guo, H.; Lei, Y. Method Comparison of Weibull Function for Estimating and Predicting Diameter Distribution of Quercus mongolica Stands. Sci. Silvae Sin. 2016, 52, 64-71.

27. Duan, A.; Zhang, J.; Zhang, X.; He, C.Y. Stand diameter distribution modelling and prediction based on Richards function. PLoS ONE 2013, 8, e62605. [CrossRef] [PubMed]

28. Gobakken, T.; Næsset, E. Estimation of diameter and basal area distributions in coniferous forest by means of airborne laser scanner data. Scand. J. For. Res. 2004, 19, 529-542. [CrossRef]

29. Maltamo, M.; Suvanto, A.; Packalén, P. Comparison of basal area and stem frequency diameter distribution modelling using airborne laser scanner data and calibration estimation. For. Ecol. Manag. 2007, 247, $26-34$. [CrossRef]

30. Maltamo, M.; Gobakken, T. Predicting tree diameter distributions. In Forestry Applications of Airborne Laser Scanning; Springer: Dordrecht, The Netherlands, 2014; pp. 177-191.

31. Næsset, E.; Gobakken, T. Estimating forest growth using canopy metrics derived from airborne laser scanner data. Remote Sens. Environ. 2005, 96, 453-465. [CrossRef] 
32. Siipilehto, J.; Mehtätalo, L. Parameter recovery vs. parameter prediction for the Weibull distribution validated for Scots pine stands in Finland. Silva Fenn. 2013, 47, 22. [CrossRef]

33. Arias-Rodil, M.; Diéguez-Aranda, U.; Álvarez-González, J.G.; Pérez-Cruzado, C.; Castedo-Dorado, F.; González-Ferreiro, E. Modeling diameter distributions in radiata pine plantations in Spain with existing countrywide LiDAR data. Ann. For. Sci. 2018, 75, 36. [CrossRef]

34. Wang, S.; Liu, D. Application of Markov Theory in Forecasting the Diameter of Larix gmelinii Plantation. For. Sc. Technol. 1991, 5, 10-12.

35. Breidenbach, J.; Gläser, C.; Schmidt, M. Estimation of diameter distributions by means of airborne laser scanner data. Can. J. For. Res. 2008, 38, 1611-1620. [CrossRef]

36. Zhao, H. Study on Dynamic Modeling of Larch Plantation; Hebei Agricultural University: Hebei, China, 2001.

37. Liu, C.; Zhang, L.; Davis, C.J.; Solomon, D.S.; Gove, J.H. A finite mixture model for characterizing the diameter distributions of mixed-species forest stands. For. Sci. 2002, 48, 653-661.

38. Chen, W. Tree size distribution functions of four boreal forest types for biomass mapping. For. Sci. 2004, 50, 436-449.

39. Elith, J.; Phillips, S.J.; Hastie, T.; Dudík, M.; Chee, Y.E.; Yates, C.J. A statistical explanation of MaxEnt for ecologists. Divers. Distrib. 2011, 17, 43-57. [CrossRef]

40. Wu, J. The Beauty of Mathematics, 2nd ed.; Posts and Telecom Press: Beijing, China, 2014.

41. Xiao, X.; McGlinn, D.J.; White, E.P. A Strong Test of the Maximum Entropy Theory of Ecology. Am. Nat. 2015, 185, E70-E80. [CrossRef]

42. Xiao, X.; O'Dwyer, J.P.; White, E.P. Comparing process-based and constraint-based approaches for modeling macroecological patterns. Ecology 2016, 97, 1228-1238. [CrossRef] [PubMed]

43. Newman, E.A.; Harte, M.E.; Lowell, N.; Wilber, M.; Harte, J. Empirical tests of within-and across-species energetics in a diverse plant community. Ecology 2014, 95, 2815-2825. [CrossRef]

44. Ding, G. Model System of Growth Yield of Chinese Fir Plantation in Guizhou. J. Northeast. For. Univ. 1997, 5, 43-49.

45. Zhang, J. Study on Theoretical Growth Equation and Diameter Structure Model; Science Press: Beijing, China, 2004.

46. Campbell, I. Chi-squared and Fisher-Irwin tests of two-by-two tables with small sample recommendations. Stat. Med. 2007, 26, 3661-3675. [CrossRef]

47. Haynes, W. Wilcoxon rank sum test. Encycl. Syst. Boil. 2013, 2354-2355. [CrossRef]

48. Levine, R.D.; Tribus, M. The Maximum Entropy Formalism; The MIT Press: Cambridge, UK, 1978; pp. 15-118.

49. Gu, Q. The maximum entropy principle for radiation fields. J. Shenzhen Univ. Sci. Eng. 2011, 28, $283-294$.

50. Jaynes, E.T. Information theory and statistical mechanics. Phys. Rev. 1957, 106, 620. [CrossRef]

51. Jaynes, E.T. Information theory and statistical mechanics. II. Phys. Rev. 1957, 108, 171. [CrossRef]

52. Jang, W.; Eskelson, B.N.I.; Marshall, P.L.; Moss, I.A. stand table projection system for interior Douglas-fir in British Columbia, Canada. For. Ecol. Manag. 2018, 409, 434-443. [CrossRef]

53. Leduc, D.J.; Matney, T.G.; Belli, K.L.; Baldwin, V.C. Predicting Diameter Distributions of Longleaf Pine Plantations: A Comparison between Artificial Neural Networks and Other Accepted Methodologies; Res. Pap. SRS-25; US Department of Agriculture, Forest Service, Southern Research Station: Asheville, NC, USA, 2001; Vloume 25, p. 24.

54. Abbasi, B.; Rabelo, L.; Hosseinkouchack, M. Estimating parameters of the three-parameter Weibull distribution using a neural network. Eur. J. Ind. Eng. 2008, 2, 428-445. [CrossRef]

55. Cai, S.; Kang, X.; Zhang, L. Simulation of trunk diameter distribution for three broadleaved trees based on artificial neural networks. Int. J. Adv. Comput. Technol. 2012, 4, 520-527.

56. Cai, S.; Kang, X.; Zhang, L.X.; Gong, Z.W.; Qin, L.; Chen, P.T. A model for tree diameter distribution in stands based on artificial neural network. In Proceedings of the 2010 International Symposium on Intelligence Information Processing and Trusted Computing, Huanggang, China, 28-29 October 2010; pp. 332-336. 
57. Yang, F.; Yue, Z. Kernel density estimation of three-parameter Weibull distribution with neural network and genetic algorithm. Appl. Math. Comput. 2014, 247, 803-814. [CrossRef]

58. Diamantopoulou, M.J.; Özçelik, R.; Crecente-Campo, F.; Eler, Ü. Estimation of Weibull function parameters for modelling tree diameter distribution using least squares and artificial neural networks methods. Biosyst. Eng. 2015, 133, 33-34. [CrossRef]

(C) 2019 by the authors. Licensee MDPI, Basel, Switzerland. This article is an open access article distributed under the terms and conditions of the Creative Commons Attribution (CC BY) license (http://creativecommons.org/licenses/by/4.0/). 